\title{
Assessment of the State of Water and Land Resources in Azerbaijan
}

\author{
RAE Aliyev Z.H \\ Institute of Erosion and Irrigation of ANAS, Baku \\ zakirakademik@mail.ru
}

\begin{abstract}
The results of the study, which show that up to $96 \%$ of the irrigated land is watered mainly with traditional methods of irrigation (furrows and fillings) by surface methods, and the rest up to 5\%, while in irrigated fields it is watered with the use of progressive water-saving low-intensity Irrigation systems. Therefore, in the fields, the level of groundwater grows every day.
\end{abstract}

Keywords: irrigation, arable land, groundwater, erosion, salinization, humus, etc.

\section{INTRODUCTION}

The total area of the republic is 8641500 hectares of land, of which 55 percent of it, ie 4756500 hectares, is made suitable for agriculture. Or 16.6 percent of the total area or 1,432,600 hectares, constitutes the irrigated land.

$1,804,800$ hectares of the total land balance belongs to arable land suitable for agriculture. It should be noted that 181600 ha of that available total area of arable land are under occupation by second-hand Armenian aggressors. 224,700 hectares of arable land, perennial crops, 11,700 hectares of hayfields, pastures 2,560.0 thousand hectares, 45.7 hectares of fallow areas. In the country of the yards there are 258,100 hectares (227,600 hectares of arable land), 1,038,800 hectares are included in the proportion of forest plantations.

In connection with the increase in the population, now numbering about 10 million people, the land is used outside of agricultural projects and allocated for the construction of individual buildings and structures, severely frolicked individual types of soil erosion, and on the other hand, the rise in the groundwater table as a result of the rise In raising the sea level, improperly managing agroameliorative measures, production areas in individual farms, and applying with violation of the rules of ecologically safe cultivation technology to Ultur, and agricultural machinery, the area of arable land per capita is decreasing from year to year. [1,2,4. If allocated to the share of one person in 1959 was 0.36 hectares of arable land, this figure was in 19700.23 hectares, in 19790.21 hectares, while in 2006 it decreased to 0.155 hectares [3 ].

$60 \%$ of the territory of the entire territory is located on the mountainous part of the republic. Because of the impact of natural and anthropogenic factors here, one can also meet in all types of erosion [5]. Based on the results of our numerous studies in the study of the patterns of development of land degradation problems, and even the landscape in some regions, it was established that the erosion process is very widespread (especially in the mountainous terrain) in the country.

At present, more than $42.8 \%$ of the entire territory of the republic, $70-85 \%$ in some regions suffer from different degrees of erosion [5, 6]. One of the biggest factors of water and irrigation erosion.

Dominating the furrow irrigation and irrigation in the republic, agronomic measures, irrespective of any protection of land, agriculture, horticulture and livestock, cause soil erosion [2, 7].

However, in the country, faced with acute water shortage conditions.

The country's water resources are 32.5 billion m3. In low-water years, this figure decreases by 23.16 billion. M3.

The volume of water resources in the country is only $30 \%$, and the remaining $70 \%$ flow through neighboring countries [4]. It should be noted that in the face of constant water shortages, the sharply 
uneven distribution of water in the country, despite the economic and environmentally effective irrigation of crops, is not primitive, traditional or pouring carried out by irrigation.

The results of the study revealed that up to $96 \%$ of irrigated land is watered mainly by traditional methods of irrigation (furrows and overlapping) by surface methods and the rest up to 5\% - while in irrigated fields it is watered using progressive water-saving low-intensity irrigation systems. Therefore, in the fields, the level of groundwater grows every day. In fact, in a number of areas, underground water, arable land, suitable for about 1000 thousand hectares were salinized, which caused particular danger in violation of the country's ecological balance.

Currently, more than 53 thousand hectares of sown areas of the Kura-Araks lowland suffered great danger as heavily saline soils due to flooding, where homestead plots of the population of these regions of Azerbaijan left the crop rotation where thorough cleaning of those soils from lifethreatening salts of various kinds is required. $[2,4,6]$.

The results of the monitoring studies revealed comparative indicators for water supply, 3 Transcaucasian states: Georgia, Armenia and Azerbaijan, a follower of water resources at their 70, 25 and 10 billion $\mathrm{km} 3$, respectively.

The annual per capita water resources in these countries are as consecutive 11000,3000 , and 1500m3 / person. According to the research, 2020, show annual water resources per capita of Azerbaijan in turn is 2 times less than in Armenia, and 7 times less than in Georgia.

It is believed that water resources are very important in the development of the economy of each country, especially in the industrial-production sphere, and in agriculture is a key element of life.

2. Degrees of soil erosion by erosion and methods of its struggle in Azerbaijan

\section{Degrees of Soil Erosion by Erosion:}

Degree 1 - weak erosion - meets mainly in the form of a surface washout invisible to the eyes. Its traces, in the form of small ruts and sediments, are easily aligned in the process of agro technical processing of soils.

Degree 2 - moderate erosion - manifests itself in the form of ruts, changes the level of humus in the soil, reducing its amount, worsening the physico-chemical properties of soils. This process does not affect the formation of the relief.

Degree 3 - medium erosion - intensively destroys the arable-humus layer, reaching even the parent rock. Ravens and grooves are numerous, deep and cannot be corrected as a result of the processing process, causing the formation of undulating slopes.

Degree 4 - severe erosion - destroys the entire soil profile, ruts and grooves are formed, which are increasingly entering the layer of the parent rock. As a result, there is a so-called erosion landscape with a characteristic breakdown of the soil cover and the formation of ravines.

Degree 5 - very strong erosion - blurs the entire soil profile, together with part of the foot. This leads to a strong fragmentation of the soil cover, the creation of a dense network of gullies, and to the transformation of agricultural territory into junk land.

\section{Degrees of Soil Destruction by Wind Erosion:}

Degree 1 - weak erosion is caused to a small blowing from the soil of the best and most valuable colloidal, clay and dust particles. Blowing it practically does not affect the condition of the soil;

Degree 2 - moderate erosion begins to limit, to some extent, the humus of the soil due to the blowing out of a large number of mineral and organic components, in comparison with weak erosion.

Degree 3 - average erosion can significantly reduce the humus content due to a significant amount of mineral and organic particles and cause damage to crops.

Degree 4 - severe erosion leads to changes in the soil profile. These soils are subject to strong blowing, have a clearly reduced level of humus, which accumulates in the wind deposits.

Degree 5 - very strong erosion leads to the formation of dunes. Strongly eroded land should be completely covered with forests. 
Such presentations became the basis for the development of a program to protect land from erosion degradation for the whole country. Large-scale accounting was conducted only in those places for which plans or projects for development and organization of the economy are being developed. In this model does not allow for.

\section{RESEARCH METHODOLOGY}

Degrees of soil destruction by wind erosion:

In order to study the distribution areas and intensity of erosion processes development, we used field and laboratory methods of investigation.

The phenomenon of soil erosion and areas of its distribution was relatively comparatively geographically, stationary and semi-stationary.

The determining role of the terrain in the development and development of soil erosion is well known. The most pronounced factors in the nature of mountainous areas are the slope of the surface, the depth of local bases and the exposure of slopes. Therefore, on the basis of topographic maps at a scale of 1 : 50,000 , the same name map of erosion factors was compiled for the study area.

When drawing a map of surface slopes, the following gradations were adopted: $0-30 ; 3-50 ; 5-70 ; 7$ $100 ; 10-150 ; 15-200 ; 20-250 ; 25-300 ; 30-450$; and more than 450 .

For the distribution of land along the slopes of the surface, indicators of the average weighted slope value proposed by MN Zaslavsky (1979)

Жср.взв $=\frac{i_{1} s_{1}+i_{2} s_{2}+\cdots+i_{n} s_{n}}{100}$

Where

Жср.взв is the average weighted value of slopes

И1; and 2; In-the slope of the outlined contours,

$\mathrm{C} 1 ; \mathrm{C} 2$; $\mathrm{cH}$ - area of allocated contours, \% of total area.

Maps of the depths of local erosion bases were compiled with the definition of the excess of watersheds above the riverbeds and their tributaries, as well as large ravines and suhodalis. To compile this map, the following gradation was adopted: $0-50 ; 50-100 ; 100-150 ; 150-200 ; 200-250$; 250-300, 300-400; 400-500 and more than $500 \mathrm{~m}$. [5]

The map of the slope exposure is compiled on a topographic basis and is distinguished: northern, north-eastern, north-western, eastern, southern, south-east, south-west exposure.

In carrying out soil-erosion studies, the classification of SS Sobolev was used (the description of which is given in the book of IF Sadovnikov 1954). Taking into account this classification, the soils in terms of degree of erosion were distinguished as follows:

1. Undiluted soils - there are all genetic horizons, destruction is not observed;

2. Weakly washed soils - no more than half of the humus horizon A is washed away, formation of jet erosion is observed on the soil surface.

3. Medium-washed soils - more than half of the genetic horizon A is absent.

4. Strongly washed soils - the horizon A is completely washed away, and the horizon B partially overlaps.

3. Improvement of eroded soils of pastures of Azerbaijan

The territory of the Republic of Azerbaijan is located in the eastern part of the Transcaucasus, this includes the Greater and Lesser Caucasus regions, the Talysh zone, the Kura depression. The total area of the republic is 86.6 thousand $\mathrm{km} 2$, about $40 \%$ of the land area is made up of plains, the remaining $60 \%$ is foothill and mountainous.

The climatic conditions of the republic are diverse as a mountainous country, the republic at the same time possesses vast lowlands, valleys and due to the diversity of the relief surface it has a diverse 


\section{RAE Aliyev Z.H}

climate. From the invasion of cold air masses from the north, the republic is protected by the main Caucasian ridge.

Depending on the altitude, climatic conditions vary. With a rise in the mountains, the average air temperature drops. Of the 11 types of climate established on the Earth's Globe, we have 9 under the types of climate, there is no climate of savannas and climate of tropical forests.

Typical types of soils are mountain meadow sod, further mountain forest soils, gray-brown in the foothills and foothill plains, gray-brown in the arid zone, yellow silts in the Talysh zone.

Despite the small area of the republic has a variety of natural conditions and rich natural resources. One of the natural resources in Azerbaijan is pasture. The area of pastures in the republic is $22.3 \%$ of the total area.

Summer pastures are 621 thousand hectares, winter 1.5 million hectares, priselsky pastures and hayfields are about 1 million hectares.

It is known that the Republic of Azerbaijan from ancient times is distinguished by the livestock sector.

Our region with rich natural pastures and pastures located in the Alpine zones is a natural resource. However, due to various circumstances, including soil erosion, these natural forage resources lose their potential fertility. One of such circumstances is soil erosion.

Erosion is destruction, erosion, as a geological term is the destruction of the upper fertile soil layer under the influence of wind and water.

The upper layer of the earth's crust as a result of occurring in the nature of processes undergoes various changes. This process can proceed as a normal phenomenon of nature, also intensively as a result of anthropogenic load. In any of the 2 cases, the topsoil is flushed.

Irrespective of the type of erosion, the most developed fertile upper accumulative horizon is carried away.

Along with water flows and a solid phase of soils, nutrients with a finely dispersed fraction are carried away and, depending on the degree of erosion, the damage caused by erosion is different. It should also be noted that in addition to watererosion the appearance of wind erosion-deflation-is also great.

Wind erosion intensively manifests itself in the arid zone, where dry climate, increased wind regime, insignificant precipitation contribute to degradation of the vegetation cover.

The intensity of development of wind erosion in comparison with water is small. However, the damage caused by wind erosion to agriculture is enormous.

Wind erosion on one side promotes the blowing of the soil, on the other hand, the accumulation of particles in the form of a hill, the moving sands fill up with vegetables, gravel crops, roads, construction sites, squally winds tear roofs off houses.

Natural fodder lands located on eroded slopes have low productivity.

Winter pastures of drylands do not provide livestock with quantitative and qualitative feed

Methods for improving natural hayfields and pastures are divided into 2 main groups: superficial and radical improvement. By superficial improvement means measures for keeping hayfields and pastures in a cultural state and increasing their yield without disturbing the natural turf.

The system of superficial improvement of natural hayfields and pastures is to improve the water, air and food regimes, care for the grass stand, for the longest time to keep fodder in a state of economic value. Surface improvement is advisable in meadows, where $20-25 \%$ of valuable forage grasses are preserved in the grass stand.

On hayfields and pastures with aworse herbage, a superficial improvement does not give the proper effect, and a thorough investigation should be carried out on them.

\section{REFERENCES}

[1] Aliyev Z.H. Aerospace monitoring of soil cover dynamics // Aerospace methods in soil science and their use in agriculture. - Moscow: Nauka, 1990. - P. 55-60. 
[2] B.H. Aliyev, Z.H. Aliyev, A.Dj. Musayev., A.A. İbrahimov. Dangerous erosion of the mountain zone and ways to increase the efficiency of agriculture land eroded. Baku2003. $80 \mathrm{p}$.

[3] Aliyev Z.H., Djafarov A.B. Agroecological assessment and grouping of pasture lands of Azerbaijan, Sat. Scientific works of the SRI GTM 29th volume Iftu-2009 p.133-139

[4] Vinogradov B.V. Aerospace monitoring of ecosystems // Moscow: Nauka, 1984. 320

[5] Vinogradov B.V. Aerospace monitoring of ecosystems // Moscow: Nauka, 1984. 320 p.

[6] Zaslavsky M. Erosiology, Moscow, Higher School Publishing House, 1963 st.212.

[7] MamedovG.Sh. Land reform in Azerbaijan: legal and scientific-environmental issues. Elm Publishing House, Baku-2000, pt.372. 